\title{
Study on Enzymatic and Electrochemical Properties of Cellulase Immobilized with Multi-Walled Carbon Nanotubes as Sensor for Catechol
}

\author{
Junling Wang ${ }^{1}$, Jingnan Wang ${ }^{1}$, Wenxu $\mathrm{Li}^{2}$, Chuang Yang ${ }^{2, *}$ \\ ${ }^{1}$ College of Biological and Pharmaceutical Engineering, Jilin Agricultural Science and Technology \\ University, Jilin 132101, China \\ ${ }^{2}$ College of Agriculture, Jilin Agricultural Science and Technology University, Jilin 132101, China \\ *E-mail: yc2996251@,sina.com and yangchuang@jlnku.edu.cn
}

doi: $10.20964 / 2021.04 .62$

Received: 3 January 2021 / Accepted: 22 February 2021 / Published: 28 February 2021

This work focused on studying the enzymatic and electrochemical properties of cellulase immobilized on carboxylated MWCNTs (cellulase/c-MWCNTs). The morphology and attachment of impurities, enzymatic and electrochemical properties of c-MWCNTs and cellulase/c-MWCNTs were studied. Results of morphology and attachment of impurities by FESEM and FTIR showed that the c-MWCNTs were prepared in bundles structure with porous and smooth surface but after cellulase immobilization by entrapment inside c-MWCNTs matrix, the prepared cellulase/c-MWCNTs displayed the rougher surface with more saturated pores. These results of FTIR evidenced to form $\mathrm{N}-\mathrm{H}$ and $\mathrm{O}-\mathrm{H}$ stretching vibrations of cellulase, and presence of nitriles, amide group and aliphatic amide bond in cellulase/cMWCNTs structure that confirmed to successfully immobilization of cellulase enzyme on the cMWCNTs side walls. Study of enzymatic properties showed that the optimum condition for electrochemical study of the cellulase/c-MWCNTs was concentration of $4 \mathrm{mg} / \mathrm{ml}, \mathrm{pH} 4$ and temperature of $35^{\circ} \mathrm{C}$. Electrochemical study of cellulase/c-MWCNTs for detection catechol showed linear range and detection limit were obtained 10 to $160 \mu \mathrm{M}$ and $0.004 \mu \mathrm{M}$, respectively. The comparison of sensing properties of cellulase/c-MWCNTs and other reported catechol sensors indicated the comparable electrochemical properties. Low detection limit for determination of catechol on the cellulase/cMWCNTs can be due to formation of fast electron transfer pathways between the cellulase/c-MWCNTs electrode and the electrolyte.

Keywords: Enzymatic property; Electrochemical sensor; Cellulase; Carbon nanotubes;Cyclic voltammetry; Amperometry

\section{FULL TEXT}


(C) 2021 The Authors. Published by ESG (www.electrochemsci.org). This article is an open access article distributed under the terms and conditions of the Creative Commons Attribution license (http://creativecommons.org/licenses/by/4.0/). 